\title{
A survey of owners' perceptions of fear of fireworks in a sample of dogs and cats in New Zealand
}

\author{
AR Dale ${ }^{*}$, JK Walker ${ }^{*}$, MJ Farnworth ${ }^{*}$, SV Morrissey ${ }^{*}$ and NK Waran ${ }^{*}$
}

\begin{abstract}
AIMS: To establish reliable information regarding the behavioural responses of dogs and cats to fireworks in New Zealand; record interventions used by owners, and their perceived efficacies; and establish the prevalence of firework-related injury, and quantify owners' attitudes towards fireworks.
\end{abstract}

METHODS: A questionnaire targeting dog and cat owners was distributed via the Auckland Society for the Prevention of Cruelty to Animals (SPCA) Animals Voice magazine and 25 veterinary clinics. The questionnaire covered demographics of animals, fear of fireworks, severity of the fear, and behaviours exhibited. Also included were treatments tried, source and perceived efficacy, prevalence of injury, and owners' attitudes towards the sale of fireworks for private use.

RESULTS: From a total of 8,966 questionnaires distributed, 1,007 valid questionnaires were returned, representing 3,527 animals. Of these 1,635 (46\%) animals displayed a level of fear of fireworks recognisable to their owners. Owners of dogs identified a significantly higher fear response than owners of cats but the duration of these fear responses did not differ between species. Fear of fireworks frequently resulted in dogs exhibiting active fear behaviours, whereas cats were more likely to exhibit hiding and cowering behaviours. A significantly increased severity and duration of fear response over time in dogs and cats was associated with owners who comforted them when they displayed a fearful response. Only 141/890 (15.8\%) of owners sought professional treatment from a veterinarian, animal behaviourist or animal trainer for their animals, with variable efficacy. Six percent $(51 / 923)$ of animals had received physical injuries from fireworks. The majority $(837 / 1,007 ; 83 \%)$ of respondents, regardless of whether they owned a fearful animal or not, supported a ban on the sale of fireworks for private use.

CONCLUSIONS: The results provide valuable information that is, as yet, unsubstantiated in New Zealand, although potential biases exist due to the non-random selection of respondents. Differences between dogs and cats were likely due to differing responses to fear-provoking stimuli between the species. Owner-reported increase in fearful response over time for comforted animals may indicate a negative impact on the longer-term psychological welfare of their animal.

CLINICAL RELEVANCE: The greater the awareness of effective treatment plans for animals that suffer from a fear of fireworks, the greater the possibility that this fear can be reduced.

* Animal Welfare Group, Department of Natural Sciences, Unitec, Private Bag 92025, Auckland 1025, New Zealand.

$\$$ Author for correspondence. Email: adale2@unitec.ac.nz
Wider dissemination of effective owner behaviour and treatment programmes for firework fears is needed to improve levels of professional treatment for dogs and cats.

KEY WORDS: Dogs, cats, fear, fireworks, treatment

\section{Introduction}

In New Zealand, both public and private firework displays are common. The sale of fireworks for private use is governed by the Hazardous Substances and New Organisms Act 1996 (Anonymous 1996), which places limitations on such sale, designed to minimise potential harms. The fear of fireworks in animals was cited as an increasing problem in the United Kingdom due to the ubiquitous use of fireworks during many holidays and celebrations (Levine et al. 2005). Information pertaining to fear of fireworks in dogs and cats within New Zealand is not available but there remains a significant number of festivals either side of the legal period of sale ( 3 days prior to 05 November) which perpetuate the private and unpredictable use of fireworks.

Fear responses to fireworks are thought to occur due to unpredictable, intermittent and high-intensity noise (Cracknell and Mills 2008). Those authors stated that the effects of secondary stimuli such as light flashes, odours or even changes in barometric pressure on the behaviour, perception and physiology of animals remain largely unknown. Fears and phobias of noise among dogs are a behavioural problem that is commonly reported (Landsberg et al. 2003; Mills et al. 2003). For dogs, the most common feareliciting noises are thunder, fireworks and gun shots (Shull-Selcer and Stagg 1991; Landsberg et al. 2003). There are few publications on fear of noises in cats despite it being a significant issue in behavioural medicine (Bowen and Heath 2005), and none which directly addresses fear of fireworks.

Fear responses will differ between species. Dogs may, amongst other behaviours, vocalise, pant, eliminate, increase locomotion, tremble or cower (Sheppard and Mills 2003). Conversely, cats are more likely to hide, or exhibit a state of behavioural inhibition. This passivity may often be misinterpreted by cat owners as a lack of fear, especially if the cat is seen to engage in increased selfmaintenance behaviour, such as displacement grooming (Bowen and Heath 2005). Therefore, the behavioural impacts of fear of fireworks are relatively unknown in cats compared with dogs.

If fear of noises is left to progress untreated then it can develop into phobias, and will frequently also generalise to other similar 
stimuli (Blackwell et al. 2005). It is essential that effective treatment plans be implemented as animals that are repeatedly exposed to fearful events may experience decreased levels of welfare (Sheppard and Mills 2003; Hydbring-Sandberg et al. 2004; Dreschel and Granger 2005). Generic treatments, such as desensitisation programmes, for fear of noises are widely available (Cracknell and Mills 2008). Typically, fear of noises is resolved using a system of desensitisation and counter-conditioning (Mills et al. 2003; Levine et al. 2007; Levine and Mills 2008). The animal is gradually exposed to increasing volumes of the trigger stimuli, usually in association with some form of reward, ensuring a fear response is not elicited at any level (Overall 2002). This procedure typically takes several weeks or months to complete (Cracknell and Mills 2008).

There are immediate control methods available to help manage fear of noises in animals or to be used in conjunction with desensitisation. These are appealing to owners as they provide a 'quick fix' although they can lead to many owners not treating the problem in the long term (Mills et al. 2003). Veterinary medications such as sedatives and benzodiazepines are a popular choice for owners of noise-phobic dogs (Seksel and Lindeman 2001; Crowell-Davis et al. 2003; Mills et al. 2003), even though the use of sedatives is now considered outdated by some behavioural experts in the field (e.g. Overall 2002). Contrary to this, some owners find the use of even appropriate medications unacceptable, and the use of dog-appeasing pheromone (DAP; Ceva Santé Animale, Libourne Cedex, France) (Levine et al. 2007; Levine and Mills 2008), herbal preparations, Bach flower remedies and homeopathic treatments (Cracknell and Mills 2008) have all been considered.

The aim of this research was to report on owner-identified fear of fireworks in companion dogs and cats within New Zealand. In addition, we aimed to investigate owners' interpretations of their animals' fear responses, the use and perceived efficacy of distractive or preventative measures, incidences and severities of physical injuries resulting from fireworks, and respondents' views of the sale of fireworks for private use. This information is integral to the future management of the welfare of dogs and cats that exhibit fear of fireworks.

\section{Materials and methods}

A non-probability questionnaire, designed to be answered in 5 minutes, was disseminated to 8,966 available subjects via the Auckland SPCA's Animals Voice magazine (Winter issue 2005), and 25 small animal veterinary clinics throughout New Zealand (randomly selected from a database of clinics). Each clinic was sent a research information sheet and a letter requesting they distribute 100 questionnaires to their clients. Questionnaires were returned in an unmarked, postage-paid envelope, so that it was not possible to identify the source from which it was returned. All aspects of this research were approved by the Unitec Department of Natural Sciences Human Ethics Research Committee, Auckland, New Zealand.

The questionnaire was divided into four sections (see Supplementary Table $1^{1}$ ). Although respondents included information about all animals owned, only information pertinent to dogs and cats that the owner recognised as fearful of fireworks is included here. All other information was disregarded, with the exception of that pertaining to supporting a ban on the sale of fireworks for private use within New Zealand. Section 1 covered demographic information about the respondents' animal(s), including origin, species, breed, age and sex of the animal(s). Dogs were assigned to one of the New Zealand Kennel Club's seven categories of group of breed (see: www.nzkc.org.nz/dogselect), based on the owners' descriptions of the breed. Cats were categorised as either pedigree or domestic. Severity of fear of fireworks was recorded on a Likert scale (Likert 1932), where 1 was slightly scared, 2 scared, 3 very scared, and 4 extremely scared. Respondents were asked if the level of fear had changed over time, and for information regarding behaviours exhibited during firework displays (e.g. vocalising, destructive behaviour, shaking/shivering, elimination, cowering, and escape behaviours), and the duration of fear ( $1=$ the duration of the fireworks, 2 = up to 2 hours after the firework display ended, 3 = the next day, 4 = the next 2 days, $5=$ for $\geq 1$ week) in relation to the firework display.

In Section 2, treatments sought by the owner were identified, including the type, source and their perceived efficacy. This was reported on a Likert scale, where 1 was not at all, 2 mildly successful, 3 successful, 4 very successful, and 5 extremely successful. If no treatment had been sought owners were invited to explain why. Respondents were also asked to record any preventative measures tried, and if fears had generalised onto other sounds.

In Section 3, respondents were asked to record the number, type and severity of physical injuries to their pets caused by fireworks, and whether they were accidental, indirect or deliberate.

Section 4 was concerned with respondents' attendance at public firework displays, and if they took their animal(s) with them, if their family purchased fireworks for private use, and if they supported a ban on the private sale of fireworks.

A freepost address was provided and an advertisement placed in Animals Voice magazine to encourage a high rate of return. A preface to the start of the questionnaire explained the reasons for the research, that the replies were anonymous as no personal information was gathered, and thanked the respondents for their participation.

\section{Statistical analysis}

Data from the questionnaires relevant to fearful dogs and cats were entered into a Microsoft Access database, attributing a unique number identifier to each response. Statistical analysis was performed using SPSS for Windows v17 (SPSS Inc, Chicago IL, USA). If questions were not answered or answered ambiguously they were registered as missing data. Simple descriptive statistics were produced for all variables in the dataset. The data followed a non-parametric distribution, and non-parametric statistical tests were engaged. The pattern of distribution of the raw data was established using the Kolmogorev-Smirnov test of normality. Prevalence ratios of fearful behaviours were calculated with $95 \%$ CI. Cross-tabulation and $\chi^{2}$ tests of association (with Fisher's exact test, where appropriate) were used to investigate significant associations between the animals' fear responses and species, breed, gender and source. Mann-Whitney U tests were used to investigate differences between dogs and cats in relation to fear behaviour, and Spearman's rank correlation coefficient was used to investigate associations between the severity of fear responses and their duration. Significance was taken at $\mathrm{p}<0.05$. 


\section{Results}

\section{Demographic data}

Of the 8,966 questionnaires distributed 1,007 (11.2\%) surveys were returned, representing 3,527 animals. Of the respondents, 890/1,001 (88.9\%) owned animals that were fearful and $111 / 1,001(11.1 \%)$ had no animals that were fearful of fireworks. Of those animals represented, 1,635 (46\%) were identified, by their owner, as fearful of fireworks (684 dogs and 951 cats). These individuals were isolated for further analysis. The mean age of fearful animals was 6.9 (SD 0.17) years for dogs and 6.8 (SD 0.15 ) years for cats. Details of demographic data are summarised in Table 1.

\section{Fear response to fireworks}

Fear behaviours reported during displays included hiding, shivering/trembling, escaping or running away, vocalising, elimination, and destructive behaviour. Dogs were significantly more likely to perform destructive behaviours, shiver/tremble, vocalise, cower,

Table 1. Information on breed and source of dogs and cats reported as fearful of fireworks, by respondents to a self-selected questionnaire. Discrepancies in the data are due to invalid or missing responses.

\begin{tabular}{|c|c|c|c|c|c|}
\hline Dogs & $\mathbf{n}$ & $\%$ & Cats & $\mathbf{n}$ & $\%$ \\
\hline \multicolumn{6}{|l|}{ Breed } \\
\hline Toy & 51 & 7.5 & Pedigree & 124 & 13.0 \\
\hline Terrier & 151 & 22.2 & Domestic & 827 & 87.0 \\
\hline Gundog & 117 & 17.2 & Total $^{\mathrm{a}}$ & 951 & 100 \\
\hline Hound & 30 & 4.4 & & & \\
\hline Working & 171 & 25.2 & & & \\
\hline Utility & 73 & 10.7 & & & \\
\hline Non-sporting & 22 & 3.2 & & & \\
\hline Unknown & 65 & 9.6 & & & \\
\hline Total $^{\mathrm{a}}$ & 680 & 100 & & & \\
\hline \multicolumn{6}{|l|}{ Source } \\
\hline Breeder & 256 & 38.9 & & 88 & 9.8 \\
\hline Pet shop & 53 & 8.1 & & 103 & 11.5 \\
\hline SPCA & 101 & 15.3 & & 225 & 25.1 \\
\hline Other & 248 & 37.7 & & 481 & 53.6 \\
\hline Totala & 658 & 100 & & 897 & 100 \\
\hline
\end{tabular}

a Total number of responses for each category

SPCA $=$ Society for the Prevention of Cruelty to Animals and urinate or defaecate than cats. Cats, however, were significantly more likely than dogs to hide and/or attempt to escape (Table 2).

On the Likert scale for severity of fear, the median for dogs was 3 (minimum 1, maximum 4), and the mean 2.89 (SD 0.04). For cats the median was 3 (minimum 1 , maximum 4 ), and the mean 2.62 (SD 0.03). The distributions within the two groups differed significantly $(\mathrm{z}=-5.6 ; \mathrm{p}<0.0001)$, and comparison of the mean ranks indicated that dogs displayed a more owner-identifiable fear response to fireworks than cats.

The duration of fear for dogs (median 2, mean 1.83, SD 0.044) and cats (median 2, mean 1.92, SD 0.038) did not differ $(\mathrm{z}=-1.587 ; \mathrm{p}=0.112)$. There was a positive correlation between score for level of fear identified by owners and duration of fear response $(r=0.407 ; \mathrm{p}<0.01)$.

There was no association between sex and fear response for dogs $(\mathrm{z}=-0.832 ; \mathrm{p}=0.405)$ or cats $(\mathrm{z}=-0.834 ; \mathrm{p}=0.444)$. However, for dogs $(\mathrm{r}=0.210 ; \mathrm{p}<0.01)$ but not cats $(\mathrm{r}=-0.90 ; \mathrm{p}=0.764)$ there were age-related effects. Investigation of the mean ranks suggested that dogs aged $\geq 10$ years showed increased severity of fear responses compared with dogs $<10$ years. No significant associations were found between the severity of the fear response and the origin of the animal, e.g. SPCA, pet shop, breeder $\left(\chi^{2}=2.133\right.$; $\mathrm{df}=3 ; \mathrm{p}=0.545)$. The level of fear in 572/1,635 (35\%) animals was reported to have increased over time, 735/1,635 (45\%) had not increased over time, and the remaining $20 \%$ was unknown.

\section{Owners' interventions for dogs and cats displaying fear of fireworks}

Distraction measures utilised by owners of the 1,635 dogs and cats during fireworks were keeping their animal inside (92.1\%), comforting the animal (79.3\%), keeping the curtains/blinds shut $(71.3 \%)$, using music or television $(58.0 \%)$, confining the animal to one room (23.6\%), and not attempting any distraction measures $(1.0 \%)$. Dog owners were more likely to use music or television as a distractive technique $\left(\chi^{2}=11.513 ; \mathrm{df}=1 ; \mathrm{p}=0.001\right)$, whereas owners of cats were less likely to employ any type of distractive techniques $\left(\chi^{2}=6.383 ; \mathrm{df}=1 ; \mathrm{p}=0.012\right)$.

The level of the fear response displayed by animals was associated with the percentage of owners who comforted their animals during firework displays $\left(\chi^{2}=11.775 ; \mathrm{df}=2 ; \mathrm{p}<0.005\right)$, with animals receiving comfort from their owners showing an increased fearful response. Owners whose animals' fear responses to fireworks had increased over time were more likely to have comforted their ani-

Table 2. Number (percentage) of dogs $(n=684)$ compared with cats $(n=951)$ that displayed fear behaviours identified by their owners as being subsequent to and associated with firework displays.

\begin{tabular}{|c|c|c|c|c|c|c|}
\hline \multirow[b]{2}{*}{ Behaviour } & \multicolumn{2}{|c|}{ Dogs } & \multicolumn{2}{|c|}{ Cats } & \multirow[b]{2}{*}{$\mathbf{P}_{\text {-value }} \mathbf{a}^{\mathbf{a}}$} & \multirow[b]{2}{*}{ Prevalence ratio $^{\mathrm{b}}(95 \% \mathrm{Cl}$} \\
\hline & Yes (\%) & No (\%) & Yes (\%) & No (\%) & & \\
\hline Hiding & $483(71)$ & $201(29)$ & $806(85)$ & $145(15)$ & 0.0001 & $0.83(0.78-0.88)$ \\
\hline Shivering/trembling & $505(74)$ & $179(26)$ & $379(40)$ & $572(60)$ & 0.0001 & $1.85(1.69-2.02)$ \\
\hline Escape/run away & $185(27)$ & $499(73)$ & $442(46)$ & $509(54)$ & 0.0001 & $0.63(0.54-0.72)$ \\
\hline Vocalising & $185(27)$ & $499(73)$ & $119(13)$ & $832(87)$ & 0.0001 & $2.30(1.89-2.86)$ \\
\hline Urination/defaecation & $37(5)$ & $647(95)$ & $28(3)$ & $923(97)$ & 0.014 & $1.84(1.13-2.97)$ \\
\hline Cowering & $321(47)$ & $363(53)$ & $370(39)$ & $581(61)$ & 0.001 & $1.21(1.07-1.35)$ \\
\hline Destructive behaviour & $39(6)$ & $645(94)$ & $18(2)$ & $933(98)$ & 0.0001 & $3.01(1.70-5.12)$ \\
\hline
\end{tabular}

a Significance of difference between dogs and cats

b Estimated occurrence of behaviour in dogs relative to cats 
mals when they displayed a fear response $(\mathrm{z}=-3.487 ; \mathrm{p}<0.0001)$. Those animals were exhibiting fearful responses for longer periods of time than animals whose owners did not comfort them when they exhibited fearful responses $(\mathrm{z}=-2.087 ; \mathrm{p}<0.05)$.

Only 141/890 (15.8\%) respondents sought professional help from a veterinarian, animal behaviourist or animal trainer for their animal's fear of fireworks (Table 3). Of those owners the majority sought help from their local veterinarian. Efficacy of treatment was perceived by the majority to be ineffective, and no respondents indicated the treatment was extremely successful. No association was found between levels of efficacy and the source of advice $\left(\chi^{2}=3.538 ; \mathrm{df}=3 ; \mathrm{p}=0.316\right)$. Of the respondents who obtained professional help for their animal's fear of fireworks most were prescribed medication, of which 29\% (25/86) were prescribed sedatives. The prescribed medication did not influence the efficacy of treatment $(\mathrm{z}=-0.558 ; \mathrm{p}=0.577)$. Only 13 owners had attempted to desensitise their animal(s) to the sound of fireworks, using desensitisation recordings of noise.

Of respondents owning animals that were frightened of fireworks $658 / 969(68.0 \%)$ also reported a fear of other loud sounds. Most commonly those sounds were thunder, guns and cars backfiring. No associations were found between the severity of fear of fireworks and the fear of other loud sounds $\left(\chi^{2}=0.539 ; \mathrm{df}=3\right.$; $\mathrm{p}=0.910)$.

\section{Injuries caused by fireworks}

A total of 53 animals ( 23 dogs and 30 cats) had been physically injured as a result of fireworks, but information on the cause of the injury was provided for only 38 animals. Eight of the 38 (21\%) injuries were caused by accidental misuse, five (13\%) by deliberate misuse, and $25(66 \%)$ were an indirect result of fireworks, e.g. attempted avoidance of fireworks, causing a road traffic accident. Information on the treatment required for those injuries was obtained for 34 animals, 11 (32\%) of which required veterinary attention, five (15\%) resulted in death, four $(12 \%)$ required veterinary surgery, and one (3\%) was subject to euthanasia; the remaining 13 (38\%) did not require veterinary attention.

\section{Firework displays}

From 997 responses, 710 (71\%) respondents did not attend public firework displays. Of those who did attend public firework displays the vast majority $(283 / 287 ; 99 \%)$ attended without their animals. Fireworks were not purchased by 758/996 (76\%) respondents. Of the 237 respondents who purchased fireworks for private use, 101 (43\%) only bought sparklers. Of 1,001 respondents, $83.4 \%$ supported a ban on the private sale of fireworks, $9.7 \%$ were undecided, and $6.8 \%$ did not support such a ban. Amongst respondents that did not own an animal fearful of fireworks ( $\mathrm{n}=111$ ), $70 \%$ supported a ban.

\section{Discussion}

Recent studies have utilised owners' assessments as the primary source of information regarding behavioural problems (GunnMoore and Cameron 2004; Levine et al. 2007; Cracknell and Mills 2008), and it is thought to be the best way to estimate the actual prevalence of behavioural problems in companion animals (Fatjo et al. 2006). Ultimately, it is the owner's impression of improvement that will dictate if a treatment is deemed useful (Levine et al. 2007). However, as with any retrospective study, the results from the study presented here should be viewed with some caution as they relied on owners' recollections, sometimes over a number of years. Only 1,007 questionnaires were returned, however due to the method of distribution it was not possible to gauge how many of the original 8,966 questionnaires actually reached the target audience, and whether they originated from the magazine sample or from the selected veterinary practices. As such, the response rate cited above is highly conservative and may in fact have been much higher if, for example, not all of the 8,966 questionnaires did in fact reach animal owners. As no demographic information was collected about the owners themselves it is not possible to draw conclusions about the effects of owner variables on the perception of fear and likelihood of seeking professional help (see Supplementary Table $1^{1}$ ). Given that the sampling vehicle used was a non-probability system using subjects available primarily through a welfare-focussed organisation, it is possible that the results were biased towards those subscribed owners showing greater motivation for animal behaviour and welfare issues. Future research in this area may be better served by using a wider sample through careful selection of veterinary clinics or a larger sample of the general population.

This study revealed a high prevalence of fear of fireworks in the respondents' dogs and cats, almost half of which displayed a fear response to fireworks. This is similar to levels reported previously of 45\% (Blackwell et al. 2005) and 40\% (Voith and Borchelt 1996). The number of dogs and cats in the study reported here which showed a fear response to fireworks was evidently higher than the number for which help was sought. This supports the assertion by Mills (2005) that such problem behaviours are frequently left untreated or unmanaged.

Results from the current study suggested owners were able to recognise fear in both dogs and cats. However, fear behaviour in dogs received a higher severity score on average than cats. Therefore, dog owners engaged in distractive and/or preventative measures more frequently. It may be easier for owners to identify active fear responses in their $\operatorname{dog}(s)$, such as destruction, vocalisation, escape behaviour and elimination. As cats display more passive fear re-

Table 3. Number (percentage) of responses for each category of source of treatment used, and perceived success, of treatments for dogs and cats fearful of fireworks. Only 141/890 respondents had sought any form of help, and not all gave an evaluation of efficacy. Discrepancies in the data are due to invalid or missing responses.

\begin{tabular}{|c|c|c|c|c|c|c|c|}
\hline \multirow[b]{2}{*}{ Treatment } & \multirow[b]{2}{*}{ Total } & \multicolumn{4}{|c|}{ Owner's perception of efficacy (\%) } & \multicolumn{2}{|c|}{ Medication given (\%) } \\
\hline & & None & Mild & Moderate & Very & Yes (\%) & No (\%) \\
\hline Behaviourist & $10(7 \%)$ & $4(40 \%)$ & $6(60 \%)$ & 0 & 0 & $3(30 \%)$ & 7 (70\%) \\
\hline Trainer & $3(2 \%)$ & $1(33 \%)$ & $1(33 \%)$ & $1(33 \%)$ & 0 & 0 & $2(67 \%)$ \\
\hline Veterinarian & $111(79 \%)$ & $28(25 \%)$ & $54(49 \%)$ & $17(15 \%)$ & $4(4 \%)$ & $81(73 \%)$ & $29(26 \%)$ \\
\hline Other & $17(12 \%)$ & $2(12 \%)$ & $10(63 \%)$ & $4(25 \%)$ & 0 & $2(12 \%)$ & $14(88 \%)$ \\
\hline
\end{tabular}


sponses, such as hiding, owners consequently may be less likely to consider the fear as severe. Behavioural signs, such as decreased activity or hiding, may not be as easily recognised by owners as signs of a fear response, and hence may be under-reported (Overall et al. 2001; Blackwell et al. 2005). Interestingly, dogs and cats did not differ significantly in the duration of fear behaviour.

The fear behaviours reported in this study are consistent with the findings of other research (Beerda et al. 1997; Sheppard and Mills 2003). The behavioural sign of fear most commonly reported in dogs was trembling/shaking, possibly because they are more often reported as they are analogous with fear behaviour in humans (Blackwell et al. 2005). Also consistent were findings that animals fearful of fireworks were similarly fearful of other unpredictable noises (Blackwell et al. 2005; Estelles et al. 2005), suggesting that a fearful reaction to a specific noise may generalise to other similar sounds. It is widely considered that more severe cases and longerstanding cases of noise phobia have a poorer prognosis. However, Estelles et al. (2005) found that the severity and duration of the problem are not predictors of the success of the treatment. This should encourage clinicians to advise owners that it is never too late to treat their pet, and help relieve distress in the longer term.

From the study presented here, the increased age of dogs (significantly those $>10$ years), but not cats, was associated with increased severity of fear of fireworks. Those results could possibly be accounted for by the natural development of fearful behaviour and anxiety over time. Younger dogs, in the initial development of fears, may not display a reaction that is obvious to the owner. However, as sensitisation occurs the dog's behavioural response becomes more apparent and therefore more likely to be reported. Alternatively, older dogs may have had greater exposure to fireworks or suffered from age-related behavioural changes, e.g. cognitive dysfunction (Blackwell et al. 2005). In contrast to Marston and Bennett (2003), who identified fearfulness as the most common problem in dogs adopted from shelters, no significant associations between the severity of the fear response and where the respondent acquired their animal from were found in the study presented here.

Few (14\%) owners who reported their animal's fear of fireworks sought help for their pet, possibly because owners were unaware of treatment options (Blackwell et al. 2005), or they did not perceive the problem behaviour as significant (Morgan and Houpt 1990). Owners who did seek advice most commonly obtained it from veterinarians. The predominant use of veterinarians for advice on behavioural issues has also been found in other research (Fatjo et al. 2006). Beaver (1999) found that 68\% of clients who went to veterinary practices for any reason also asked questions in relation to canine and feline behaviour. The advice given, including advice on behavioural modification, is likely limited by the veterinarian's direct experiences of, and education concerning, behavioural and non-conventional treatments. In the present study, there was very little reported use of non-conventional therapy techniques such as use of dog-appeasing pheromone, or sound desensitisation programmes. The manner in which treatment data were collected in this questionnaire presents problems with interpretation. Respondents with multiple animals were not able to specify the individual animal receiving treatment, or the experiences of these different animals. As a result this survey was unable to identify if lack of success was associated with a dog, a cat or both. Future research is important to look at variations in efficacy of treatment between species.
There are a range of treatments that can be used for fear of fireworks in dogs and cats but the majority of respondents in the study presented here reported a low perception of efficacy of treatment. That may have been associated with the low level of usage of behavioural modification programmes, and predominance of the prescription of psychoactive medications. Research showed that maximal efficacy was often achieved through a combination of on-going behavioural therapy and pharmacological support (Crowell-Davis et al. 2003). In addition, an owner's compliance with behavioural modification programmes is an essential factor in their success or lack thereof (Levine et al. 2007; Cottam and Dodman 2009).

The manner in which owners responded to their animals' presentations of fear was associated with the fear responses. A causal relationship could not be established in the study presented here, however owners' behaviours were previously identified as important influences on fear responses in the dog (Cottam and Dodman 2009). Likewise, our results showed an association between animals whose owners comforted them and higher levels of fear, increased duration of fear, and subsequently higher levels of fear over time. Genetic predisposition to be fearful of loud noises may also be a significant contributing factor for the animal's behavioural response, however unintentional tactile or vocal reinforcement of fears commonly occurred in animals fearful of fireworks, often when the animal attempted to escape (Horwitz and Neilson 2007). Therefore owners could potentially have a negative impact on the welfare of their animal through rewarding fearful behaviours. Conversely, those animals displaying the greatest severity of fear may also be those most likely to elicit a response from their owner.

There was a small yet concerning number of animals that had physical injuries as a result of fireworks. Firework-related injuries to humans have been well documented worldwide (Clarke and Langley 1994; Eldad et al. 1995; Fogarty and Gordon 1999). The majority of the firework-associated injuries recorded in this study were indirect, or through accidental injury. Indirect injuries were commonly associated with attempts to escape from the stimulus, e.g. some dogs injured themselves as a result of striking doors, windows and fences while attempting to escape. Similar fear responses have been seen in other noise-phobia research (Crowell-Davis et al. 2003). These consequent injuries are a welfare concern.

Using fireworks as a means of deliberate abuse of animals was evident in five animals in this study. One cat was killed from having a sky rocket shot at it, and another was killed by a firework inserted in its ear. Severe injury was also noted after insertion of a firecracker under a dog's collar. Beyond the direct animal welfare issues, given the well-established link between animal and human abuse (Muscari 2004) even this low level of deliberate fireworkinduced injury is concerning. This number may also have been low due to the difficulty in diagnosing non-accidental injuries in domestic animals (Munro and Thrusfield 2001ab). Therefore further research is required to investigate the incidence and diagnostic criteria for injuries which occur as a result of the misuse of fireworks.

Of all 1,001 respondents to the survey the majority (83\%) favoured a ban on the private sale of fireworks. Respondents also raised concerns over their animals' abilities to cope with fireworks, risk of injury, and the stress they themselves had over-protected their animals during fireworks. The questionnaire did not distinguish between the effects of private $v$ s public usage of fireworks, 
but it is possible that only a ban on their sale for private use could reduce the amount of injuries to animals and people, reduce the fears that animals experience during and after them, and put New Zealand in line with several other countries that have reduced the availability of fireworks sold for private use.

In conclusion, although many dogs and cats displayed fear of fireworks relatively few owners sought treatment. The recognition of the severity of fear was greater for dogs than cats, possibly due to ease of identification. Owners' responses to that fear may inadvertently have encouraged and reinforced negative behavioural responses and, in the long term, affected the welfare of both dogs and cats. Veterinarians are encouraged to recognise and treat conditions such as noise phobias, or refer to a veterinary referral behavioural service on first presentation, to address welfare issues, and to optimise successful management.

\section{Acknowledgements}

The financial assistance of the Auckland SPCA is gratefully acknowledged. The authors would like to thank the respondents to the survey for their time, and the veterinary clinics that participated in distributing some of the questionnaires.

\section{References}

*Anonymous. Hazardous Substances and New Organisms Act 1996. New Zealand Government Printer, Wellington, NZ, 1996

${ }^{*}$ Beaver B. Canine behaviour of sensory and neural origin. Canine Behaviour: A Guide for Veterinarians. Pp 43-105. WB Saunders Co, Philadelphia, USA, 1999

Beerda B, Schilder MBH, Vanhoof JARAM, Devries HW. Manifestations of chronic and acute stress in dogs. Applied Animal Behaviour Science 52, 307-19, 1997

*Blackwell E, Casey R, Bradshaw J. Firework Fears and Phobias in the Domestic Dog. Scientific Report for the RSPCA, University of Bristol, Bristol, UK, 2005

*Bowen J, Heath S. Feline fear, anxiety and phobia problems. Behaviour Problems in Small Animals: Practical Advice for the Veterinary Team. Pp 163-77. Elsevier Saunders, Philadelphia, USA, 2005

Clarke JA, Langley JD. Firework related injury in New Zealand. New Zealand Medical Journal 107, 423-5, 1994

Cottam N, Dodman NH. Comparison of the effectiveness of a purported antistatic cape (the Storm Defender) vs. a placebo cape in the treatment of canine thunderstorm phobia as assessed by owners' reports. Applied Animal Behaviour Science 119, 78-84, 2009

Cracknell NR, Mills DS. A double-blind placebo-controlled study into the efficacy of a homeopathic remedy for fear of firework noises in the dog (Canis familiaris). Veterinary Journal 177, 80-8, 2008

Crowell-Davis S, Seibert LM, Sung W, Parthasarthy V, Curtis TM. Use of clomipramine, alprazolam, and behaviour modification for treatment of storm phobia in dogs. Journal of the American Veterinary Medical Association 222, 744-9, 2003

Dreschel NA, Granger DA. Physiological and behavioural reactivity to stress in thunderstorm-phobic dogs and their caregivers. Applied Animal Behaviour Science 95, 153-68, 2005

Eldad A, Wisoki M, Cohen H, Breiterman S, Chaouat M, Wexler MR, BenBassett H. Phosphorus burns: Evaluation of various modalities for primary treatment. Journal of Burn Care and Rehabilitation 16, 49-55, 1995

*Estelles GM, Mills DS, Coleshaw PH, Shorthose C. A retrospective analysis of relationships with severity of signs of fear of fireworks and treatment outcome in 99 cases. In: Mills D, Levine E, Landsberg G, Horwitz D, Duxbury M, Mertens P, Meyer K, Huntley LR, Reich M, Willard J (eds). Current Issues and Research in Veterinary Behavioral Medicine. Pp 161-4. Purdue University Press, W Lafayette IN, USA, 2005
Fatjo J, Ruiz-de-la-Torre JL, Manteca X. The epidemiology of behavioural problems in dogs and cats: a survey of veterinary practitioners. Animal Welfare 15, 179-85, 2006

Fogarty BJ, Gordon DJ. Firework related injury and legislation: the epidemiology of firework injuries and the effect of legislation in Northern Ireland. Burns 25, 53-6, 1999

Gunn-Moore DA, Cameron ME. A pilot study using synthetic feline facial pheromone for the management of feline idiopathic cystitis. Journal of Feline Medicine and Surgery 6, 133-8, 2004

*Horwitz DF, Neilson JC. Blackwell's Five-minute Veterinary Consult Clinical Companion: Canine and Feline Behavior. Blackwell Publishing, Ames IA, USA, 2007

Hydbring-Sandberg E, von Walter LW, Hoglund K, Swenson L, Forkman B. Physiological reactions to fear provocation in dogs. Journal of Endocrinology 180, 439-48, 2004

* Landsberg GM, Hunthausen W, Ackerman L. Fears and Phobias. Handbook of Behavior Problems of the Dog and Cat. 2nd Edtn. Pp 227-68. WB Saunders, Toronto, Canada, 2003

Levine ED, Mills DS. Long-term follow-up of the efficacy of a behavioural treatment programme for dogs with firework fears. Veterinary Record 162 , 657-9, 2008

*'Levine ED, Ramos D, Mills DS. The treatment of fear of fireworks in dogs (Canis familiaris): A prospective study. In: Mills D, Levine E, Landsberg G, Horwitz D, Duxbury M, Mertens P, Meyer K, Huntley LR, Reich M, Willard $\mathrm{J}$ (eds).Current Issues and Research in Veterinary Behavioral Medicine. Pp 211-6. Purdue University Press, W Lafayette IN, USA, 2005

Levine ED, Ramos D, Mills DS. A prospective study of two self-help CD based desensitization and counter-conditioning programmes with the use of Dog Appeasing Pheromone for the treatment of firework fears in dogs (Canis familiaris). Applied Animal Behaviour Science 105, 311-29, 2007

Likert R. A technique for the measurement of attitudes. Archives of Psychology 140, 44-53, 1932

Marston LC, Bennett PC. Reforging the bond-towards successful canine adoption. Applied Animal Behaviour Science 83, 227-45, 2003

Mills DS. Management of noise fears and phobias in pets. In Practice 27, 248-55, 2005

Mills DS, Estelles MG, Coleshaw PH, Shorthouse C. Retrospective analysis of the treatment of firework fears in dogs. Veterinary Record 153, 561-2, 2003

Morgan M, Houpt KA. Feline behaviour problems: the influence of declawing. Anthrozoos 3, 50-3, 1990

Munro HMC, Thrusfield MV. Battered pets: non-accidental physical injuries found in dogs and cats. Journal of Small Animal Practice 42, 218-26, 2001 a

Munro HMC, Thrusfield MV. Battered pets: features that raise suspicion of nonaccidental injury. Journal of Small Animal Practice 42, 279-90, 2001 b

Muscari M. Juvenile animal abuse practice and policy implications for PNPs. Journal of Paediatric Health Care 18, 15-21, 2004

*Overall KL. Noise phobias in dogs. In: Horwitz DF, Mills DS, Heath S (eds). BSAVA Manual of Canine and Feline Behavioural Medicine. Pp 164-72. BSAVA, London, UK, 2002

Overall KL, Dunham AE, Frank D. Frequency of nonspecific clinical signs in dogs with separation anxiety, thunderstorm phobias, noise phobia, alone or in combination. Journal of the American Veterinary Medical Association 219, 467-73, 2001

Seksel K, Lindeman MJ. Use of clomipramine in treatment of obsessivecompulsive disorder, separation anxiety and noise phobia in dogs: a preliminary, clinical study. Australian Veterinary Journal 79, 252-6, 2001

Sheppard G, Mills DS. Evaluation of dog-appeasing pheromone as a potential treatment for dogs fearful of fireworks. Veterinary Record 152, 432-6, 2003

${ }^{*}$ Shull-Selcer EA, Stagg W. Advances in the understanding and treatment of noise phobias. Veterinary Clinics of North America: Small Animal Practice 21, 353-67, 1991

*Voith VL, Borchelt PL. Fears and phobias in companion animals. Readings in Companion Animal Behaviour. Pp 140-52. Veterinary Learning Systems Co. Inc., Trenton NJ, USA, 1996

Submitted 06 January 2010

Accepted for publication 06 October 201

${ }^{*}$ Non-peer-reviewed 